\title{
Bacterial endosymbionts protect aphids in the field and alter parasitoid community composition
}

\author{
Lukas Rothacher, ${ }^{1,2}$ Mar Ferrer-Suay, ${ }^{3,4}$ and Christoph Vorburger ${ }^{1,2,5}$ \\ ${ }^{1}$ Institute of Integrative Biology, ETH Zürich, Universitätsstrasse 16, Zürich 8092 Switzerland \\ ${ }^{2}$ EAWAG, Swiss Federal Institute of Aquatic Science and Technology, Überlandstrasse 133, Dübendorf 8600 Switzerland \\ ${ }^{3}$ Departament de Biologia Animal, Facultat de Biologia, Universitat de Barcelona, Avenida Diagonal 645, Barcelona 08028 Spain
}

\begin{abstract}
It has become increasingly evident that many organisms rely on microbial symbionts for defense against natural enemies, but the ecological importance of defensive symbionts for natural communities still needs to be investigated. A well-known example is Hamiltonella defensa, a heritable endosymbiotic bacterium commonly found in aphids. Laboratory experiments have shown that $H$. defensa strongly protects aphids against parasitic wasps (parasitoids), although this protection is not equally effective against different species of parasitoids, or even different genotypes of the same species. These results suggest that $H$. defensa plays an important role in reducing aphid mortality by parasitoids and presumably affects the community composition of parasitoids relying on aphids as a resource. However, there is little evidence that this is indeed the case under natural conditions. We tested this in a field experiment with black bean aphids (Aphis fabae) by setting up replicated field plots with genetically identical aphids that did or did not harbor $H$. defensa and following their colonization by natural enemies over a growing season. We observed a clear reduction in parasitism of symbiont-protected aphids, particularly by the parasitoids posing the highest risk. However, protected aphids did not develop larger populations than unprotected ones, possibly reflecting the balancing effect of costs associated with harboring $H$. defensa. We also observed shifts in the parasitoid species composition on aphids protected by $H$. defensa, showing that defensive symbionts have the potential to alter the diversity and structure of food webs, with likely consequences for their function and stability.
\end{abstract}

Key words: Aphis fabae; cost of resistance; defensive symbiosis; field experiment; Hamiltonella defensa; parasitoids.

\section{INTRODUCTION}

Food webs of herbivorous insects and their natural enemies have long been used as models to study how bottom-up and top-down effects shape natural communities. Such studies have shown, for example, that the population dynamics of different herbivorous species can be linked via shared predators (Morris et al. 2004) or how parasitoids can mediate coexistence among competing hosts (van Veen et al. 2005). Other studies have elucidated how effects of host plant quality affecting herbivorous insects cascade upwards to the third and fourth trophic levels of primary and secondary parasitoids (Bukovinszky et al. 2008), or how plant defense chemicals sequestered by herbivores can interfere with predation and parasitism (reviewed in Rowell-Rahier and Pasteels 1992).

Manuscript received 13 November 2015; revised 3 February 2016; accepted 15 February 2016. Corresponding Editor: W. E. Snyder.

${ }^{4}$ Present address: American Museum of Natural History, Central Park West at 79th Street, New York, New York 10024 USA.

${ }^{5}$ E-mail: christoph.vorburger@eawag.ch
Particularly interesting are cases where members of a food web engage in symbioses, which in turn affect their interactions with other species in the food web. For example, many plants harbor endophytic fungi providing chemical protection against herbivore consumption that carries on to affect higher trophic levels as well (e.g., Omacini et al. 2001). Also the herbivores themselves may be protected from natural enemies by symbiosis, such as aphids and other sap-sucking insects that are frequently tended by ants providing defense against predators and parasitoids in return for honeydew (e.g., Stadler and Dixon 2005). Possibly the most widespread defensive symbioses in insects are those with their microbial endosymbionts. The majority of insects are infected with maternally transmitted endosymbiotic bacteria (Weinert et al. 2015), and their vertical transmission couples host and symbiont fitness to a large extent, facilitating the evolution of defense mechanisms by which symbionts protect their hosts against natural enemies. Prominent examples include defense against predatory spiders (Kellner and Dettner 1996), viruses (Hedges et al. 2008, Teixeira et al. 2008), Plasmodium (Kambris et al. 2010), fungi (Scarborough et al. 2005, Łukasik et al. 2013b), nematodes (Jaenike et al. 2010), and parasitic wasps 
(Oliver et al. 2003, Vorburger et al. 2010, Xie et al. 2011). In all of these cases, symbiont-conferred defense has been demonstrated in laboratory experiments. Even though field surveys have provided data consistent with an important role of defensive symbionts in some cases (Hansen et al. 2007, Jaenike et al. 2010, Brady and White 2013), the demonstration that symbiont-conferred defense is effective in the field is mostly outstanding. Accordingly, even less is known about community-wide effects defensive symbionts are likely to exert in natural food webs by altering species interactions. This deficit has been recognized by several authors who have hence called for field experiments addressing this issue (e.g., Oliver et al. 2014, Zytynska and Weisser 2016).

Aphids are a convenient and well-suited system for this purpose. Virtually all aphids possess the obligate endosymbiont Buchnera aphidicola, which provides them with essential amino acids (Douglas 1998). In addition to B. aphidicola aphids may harbor several facultative or secondary endosymbionts that are not strictly required for aphid survival but may confer significant ecological benefits (Oliver et al. 2010), including increased resistance to pathogens and parasitoids (reviewed in Oliver et al. 2014, Vorburger 2014). Most relevant in the present context is the gammaproteobacterium Hamiltonella defensa (Moran et al. 2005). This heritable endosymbiont occurs in approximately $40 \%$ of aphid species (Henry et al. 2015), and it strongly increases aphid resistance to parasitoids by producing phage-encoded toxins that appear to kill the parasitoids' eggs or larvae (Oliver et al. 2009). Despite the protection it provides, $H$. defensa tends not to be fixed in aphid populations and typically occurs at intermediate frequencies (Ferrari et al. 2012, Russell et al. 2013, Henry et al. 2015). There is experimental evidence that $H$. defensa imposes fitness costs on the host in the absence of parasitoids that may select against the possession of this symbiont when parasitoid abundance is low (Oliver et al. 2008, Vorburger and Gouskov 2011, Dykstra et al. 2014).

Interestingly, laboratory experiments have shown that $H$. defensa does not protect equally well against different species of parasitoids (Asplen et al. 2014, Cayetano and Vorburger 2015), and that there is among-strain variation with some strains protecting specifically against certain parasitoid species (McLean and Godfray 2015), or even against particular genotypes of the same species (Schmid et al. 2012, Cayetano and Vorburger 2013). Thus, there is now a solid body of laboratory work suggesting that defensive endosymbionts play an important role in reducing aphid mortality by parasitoids and presumably affect the community composition of parasitoids that rely on aphids as a resource. As pointed out repeatedly, however, there is still a conspicuous lack of work showing that this is indeed the case under natural conditions (Oliver et al. 2014, Vorburger 2014).

Here we present a field experiment testing for these predicted effects, using the black bean aphid (Aphis fabae) and the defensive endosymbiont $H$. defensa as a model. Black bean aphids are among the most abundant aphids in Europe and cause significant damage to crops, particularly sugar beets (Beta vulgaris) and broad beans (Vicia faba) (Blackman and Eastop 2000). Apart from predators such as ladybugs or the larvae of hoverflies and Aphidoletes midges, parasitoids are the most important natural enemies of black bean aphids. These parasitoids belong to two very distantly related groups, the subfamily Aphidiinae (Hymenoptera: Ichneumonoidea: Braconidae), and the genus Aphelinus (Hymenoptera: Chalcidoidea: Aphelinidae). Females from both groups of wasps inject a single egg into aphid nymphs or adults, from which a larva hatches that develops inside the stillactive aphid. When the aphid is consumed almost completely, the parasitoid larva kills its host and spins a cocoon inside the host's husk to pupate, forming a characteristic mummy from which the adult wasps hatch after completion of metamorphosis. By far the most important parasitoid of $A$. fabae is the aphidiine wasp Lysiphlebus fabarum, typically comprising at least $80 \%$ of parasitoids emerging from A. fabae (R. Rouchet and C. Vorburger, unpublished data).

The primary parasitoids of aphids can themselves get parasitized by secondary parasitoids. Wasps from the genera Alloxysta and Phaenoglyphis oviposit into the primary parasitoid's larva inside the live aphid, whereas wasps from the genera Asaphes, Coruna, Dendrocerus, Pachyneuron, and Syrphophagus oviposit into aphid mummies, i.e., they attack the primary parasitoid pupa inside the dead aphid. In this paper, we refer to the former group as hyperparasitoids and to the latter as mummy parasitoids, but note that the term hyperparasitoid is often also used synonymously with secondary parasitoid.

To assess the effects of defensive symbionts on parasitism under natural conditions, we set up replicated field plots with genetically identical aphids that did or did not harbor $H$. defensa and followed their natural colonization and exploitation by natural enemies over a growing season. We observed a clear reduction in parasitism of symbiont-protected aphids, particularly by the parasitoids posing the highest risk, as well as shifts in the parasitoid species composition, resulting in lower richness but higher evenness of parasitoid species emerging from protected hosts.

\section{Methods \\ Aphid lines}

Aphids reproduce clonally during the growth season and can be maintained as clones indefinitely by rearing them under summer-like conditions with long photoperiods. For the field experiment we used a $H$. defensainfected and a $H$. defensa-free subline of a single clone of $A$. fabae (lab ID A06-405). This clone had been collected in July 2006 in St. Margrethen, Switzerland, and was uninfected with any known facultative endosymbionts of aphids (Vorburger et al. 2009). The 
H. defensa-infected subline was generated in October 2008 by microinjection of hemolymph from a donor clone (A06-402) that harbored a natural infection with this symbiont, resulting in a stable, heritable infection of the newly generated line A06-405 ${ }^{\mathrm{H} 402}$. Lines A06-405 and A06-405 $5^{\mathrm{H} 402}$ were since maintained clonally in the laboratory on broad beans at $18-20^{\circ} \mathrm{C}$ and a $16 \mathrm{~h}$ photoperiod. For brevity they will be referred to as $\mathrm{H}-$ and $\mathrm{H}+$ hereafter.

\section{Experimental procedures}

Our field experiment took place during the 2013 growth season on the campus of the Swiss Federal Institute of Aquatic Science and Technology (Eawag) in Dübendorf, Switzerland. We set up $101-\mathrm{m}^{2}$ field plots in the immediate surroundings of the institute within a heterogeneous area of approximately $100 \times 50 \mathrm{~m}$ comprising meadows, trees, car parks and buildings. To account for this environmental heterogeneity, plots were set up as five pairs of one $\mathrm{H}-$ and one $\mathrm{H}+$ plot (assigned randomly) in different areas of the campus (Appendix S1: Fig. S1). The two plots of a pair were not immediately adjacent but separated by at least $10 \mathrm{~m}$ to avoid a dilution of our treatments by aphid migration between plots. Nevertheless, the plots were placed such that environmental conditions in terms of surrounding vegetation, light conditions and soil moisture were more similar between plots of the same pair than among plots from different pairs. Plots were protected from snails and slugs with a snail fence but otherwise freely accessible. Each plot was stocked on 27 May with a square array of 36 evenly spaced broad bean plants containing colonies of either $\mathrm{H}-$ or $\mathrm{H}+$ aphids (week 0 of experiment). These plants had been grown in pots in a greenhouse, inoculated with four adult aphids when they were 2 weeks old, and planted out when they were 4 weeks old and carried small colonies of aphids. Two weeks later (week 2), six plants per plot were harvested with all animals they contained and immediately sealed in a cellophane bag. The harvested plants were immediately replaced by new plants that were prepared as before, carrying $\mathrm{H}-$ or $\mathrm{H}+$ aphids according to treatment. This procedure was repeated at weekly intervals until all of the first 36 plants had been replaced and then continued by weekly harvesting the oldest six of the replacement plants until 18 September (week 16 of experiment, 15 harvests in total). As a consequence of this replacement scheme, the time the plants were out in the field plots increased initially from 2 weeks and then remained constant at 6 weeks for the rest of the experiment. Supplying additional aphids with the new plants had the purpose of maintaining a strong difference in $H$. defensa prevalence between $\mathrm{H}-$ and $\mathrm{H}+$ plots over the duration of the entire experiment, despite the potential for natural colonization by aphids and possibly migration between plots. We tested whether this approach was successful in week 9 of the experiment by collecting 36 black bean aphids per plot (one per plant wherever possible) and testing them for the presence of H. defensa by diagnostic PCR as described in Ferrari et al. (2012). We detected only three $H$. defensa-infected individuals among 180 individuals tested from $\mathrm{H}-$ plots and no uninfected individuals among the 180 aphids from $\mathrm{H}+$ plots, showing that the treatment difference persisted throughout the experiment.

The harvested plants were processed in the laboratory by counting all black bean aphids and all individuals of other aphid species that had colonized the plants, as well as all aphid mummies (hatched or unhatched). The unhatched mummies were placed in ventilated containers until they had hatched. We identified all primary and secondary parasitoid wasps to species level, using the keys listed in Müller et al. (1999). as well as new keys developed by one of us for the Charipinae (available online). ${ }^{6}$ On the freshly harvested plants, we also counted all other arthropods, but they were classified more coarsely into ladybugs (Coccinellidae; adults, larvae, and eggs), hoverflies (Syrphidae, larvae and eggs), Aphidoletes midges (larvae and eggs), spiders and ants (only two species were observed tending the aphids: Lasius niger and Myrmica rubra). All numbers were summed over the six plants to provide one weekly estimate of abundance per plot.

\section{Statistical analyses}

Weekly counts per plot of $A$. fabae, $A$. fabae mummies, and any other aphid species colonizing the plants were transformed as $\log ($ count +1$)$ to meet parametric assumptions and analyzed with linear mixed models testing for the effects of treatment, week and the treatment-by-week interactions, including plot pair and plot as random effects to account for variation among sites and for the non-independence of multiple counts from the same plot, respectively. Analyses were executed with the lme4 library (Bates et al. 2015) in R ( $R$ Core Team 2015), and the lmerTest library was used for significance tests of fixed and random effects in the models (Kuznetsova et al. 2015). Weekly counts of the different types of aphid predators and ants were too low for a similar type of analysis, we therefore aggregated the data by summing the counts from each plot over all 15 harvests and compared these total counts (again transformed as $\log [$ count +1$]$ ) between treatments using linear mixed models with plot pair included as a random term to account for the paired design.

To compare the species composition of primary parasitoids emerging from $\mathrm{H}-$ and $\mathrm{H}+$ aphids, we first analyzed the total numbers of all primary parasitoids obtained per plot with a multinomial model (multinom procedure of R library nnet; Venables and Ripley 2002), testing for the effects of treatment and plot pair and their interaction. We further tested for differences in the frequencies of all primary parasitoid species with sufficient

\footnotetext{
${ }^{6} \mathrm{http}: / /$ www.charipinaedatabase.com/
} 
numbers between the $\mathrm{H}-$ and $\mathrm{H}+$ plots for each plot pair using two-tailed $G$ tests. We used $G$ tests rather than more conventional chi-square tests because this test statistic allows the simultaneous calculation of a "pooled" (over all plot pairs) and a "heterogeneity" $G$ in replicated tests (Sokal and Rohlf 1995). An overall difference is more credible if direction and magnitude are similar across plot pairs, i.e., if heterogeneity among pairs is low. Similar comparisons of secondary parasitoids were not meaningful because their frequencies are conditional on rates of primary parasitism. Finally, we used the R package iNEXT (Hsieh et al. 2014) to compare species richness, Shannon and Simpson diversity of the overall parasitoid assemblage emerging from $\mathrm{H}-$ and $\mathrm{H}+$ aphids. Because their numbers differed dramatically between treatments, we produced rarefied estimates for same-sized samples with bootstrap confidence intervals. This was done separately for all parasitoids combined (rarefaction sample size $=200)$, for primary parasitoids $(200)$, and for secondary parasitoids (50).

\section{RESUlts}

\section{Parasitism and aphid population sizes}

The temporal trajectories of the counts of $A$. fabae and A. fabae mummies from all plots over the 2013 season are illustrated in Fig. 1. The numbers of $A$. fabae varied among plots and fluctuated considerably with a general decline in autumn toward the end of the experiment, which was reflected in significant effects of plot and week in the analysis (Table 1). However, there was no significant difference between treatments and no treatment $\times$ week interaction. The numbers of $A$. fabae mummies tended to be lowest in the first weeks, possibly reflecting the shorter time the first plants were out in the field, and they varied strongly among plots with rather idiosyncratic temporal fluctuations (Fig. 1), but there was a significant main effect of treatment with more mummies in the $\mathrm{H}^{-}$plots as well as a nearly significant treatment $\times$ week interaction (Table 1). We counted 18059 A. fabae mummies overall on the $\mathrm{H}-$ plots compared to only 1150 on the $\mathrm{H}+$ plots, and in all pairs, the total number of mummies collected over the season was higher in the $\mathrm{H}-$ plot than in the $\mathrm{H}+$ plot, as was the proportion of aphids that were parasitized (Appendix S1: Fig. S2). Only one other aphid species, Megoura viciae, colonized the plants in our experimental plots. The numbers of $M$. viciae varied among plots but there was no significant difference between $\mathrm{H}-$ and $\mathrm{H}+$ plots and their temporal occurrence was rather erratic such that there was neither a significant effect of week nor a significant treatment $\times$ week interaction (Table 1). Interestingly, we did not find any mummies of $M$. viciae during the entire experiment.

Comparisons of the total counts over the season did not provide any indication that the number of tending ants, the number of predatory syrphids and Aphidoletes midges (the most abundant group of predators) or the number of all predators combined differed between treatments (Appendix S1: Fig. S2). There was no significant correlation between the total number of tending ants observed in a plot and the overall proportion of $A$. fabae that were parasitized $(r=0.481$, df $=8, P=0.160)$.

\section{Parasitoid species composition}

From the unhatched $A$. fabae mummies we collected, a total of 9523 parasitoid wasps emerged, belonging to 20 different species. These included seven primary parasitoids and 13 secondary parasitoids, of which six were hyperparasitoids and seven mummy parasitoids (Table 2). The species composition of primary parasitoids varied among plot pairs and differed strongly between $\mathrm{H}-$ and $\mathrm{H}+$, but there was no significant treatment $\times$ plot pair interaction (likelihood ratio tests: treatment $\chi_{6}^{2}=1547.7$, $P<0.001$; plot pair $\chi_{24}^{2}=1109.5, P<0.001$; interaction $\left.\chi_{24}^{2}=16.0, P=0.888\right)$. By far the most numerous species with 8051 individuals was the primary parasitoid L. fabarum, but this species was only obtained from three $\mathrm{H}-$ plots (Fig. 2). Hence it was significantly overrepresented in plots with unprotected aphids (Table 3). The same was true for $L$. cardui: all 152 individuals came from three $\mathrm{H}$ - plots (Fig. 2, Table 3). Interestingly, L. confusus was obtained from both types of plots, but 212 of the totally 223 individuals came from a single $\mathrm{H}+$ plot (Fig. 2). They were thus overrepresented on protected aphids (Table 3). The primary parasitoid Binodoxys angelicae was found in almost all plots (Fig. 2). Overall, it was more frequently obtained from plots with protected aphids, but with highly significant heterogeneity among plot pairs (Table 3). Aphelinus chaonia was the only primary parasitoid from the Aphelinidae occurring in our experimental plots. Of the 198 individuals we obtained, 193 came from $\mathrm{H}-$ plots, where they were significantly overrepresented, albeit also with significant heterogeneity among plot pairs (Table 3). Secondary parasitoids were less numerous in $\mathrm{H}+$ plots than in $\mathrm{H}-$ plots, obviously reflecting the lower availability of parasitized aphids, but the proportion of secondary parasitoids among all parasitoids obtained did not differ significantly between treatments (paired $t$ test, $t_{4}=1.124, P=0.324$ ). The same two species, Pachyneuron aphidis and Syrphophagus aphidivorus (both mummy parasitoids), were the most common secondary parasitoids in $\mathrm{H}-$ as well as $\mathrm{H}+$ plots, all other secondary parasitoids were too rare in $\mathrm{H}+$ plots for meaningful comparisons (Fig. 2).

Considering the overall pool of parasitoid wasps that were obtained from $\mathrm{H}-$ and $\mathrm{H}+$ plots, there was no significant difference in species richness in rarefied samples of identical size (200 individuals), as indicated by their $95 \%$ confidence intervals. However, species richness for primary parasitoids was significantly higher in $\mathrm{H}-$ plots (Fig. 3A), because three common species (L. fabarum, L. cardui, and A. chaonia) were virtually restricted to $\mathrm{H}-$ plots. On the other hand, the complete lack of the 
H-
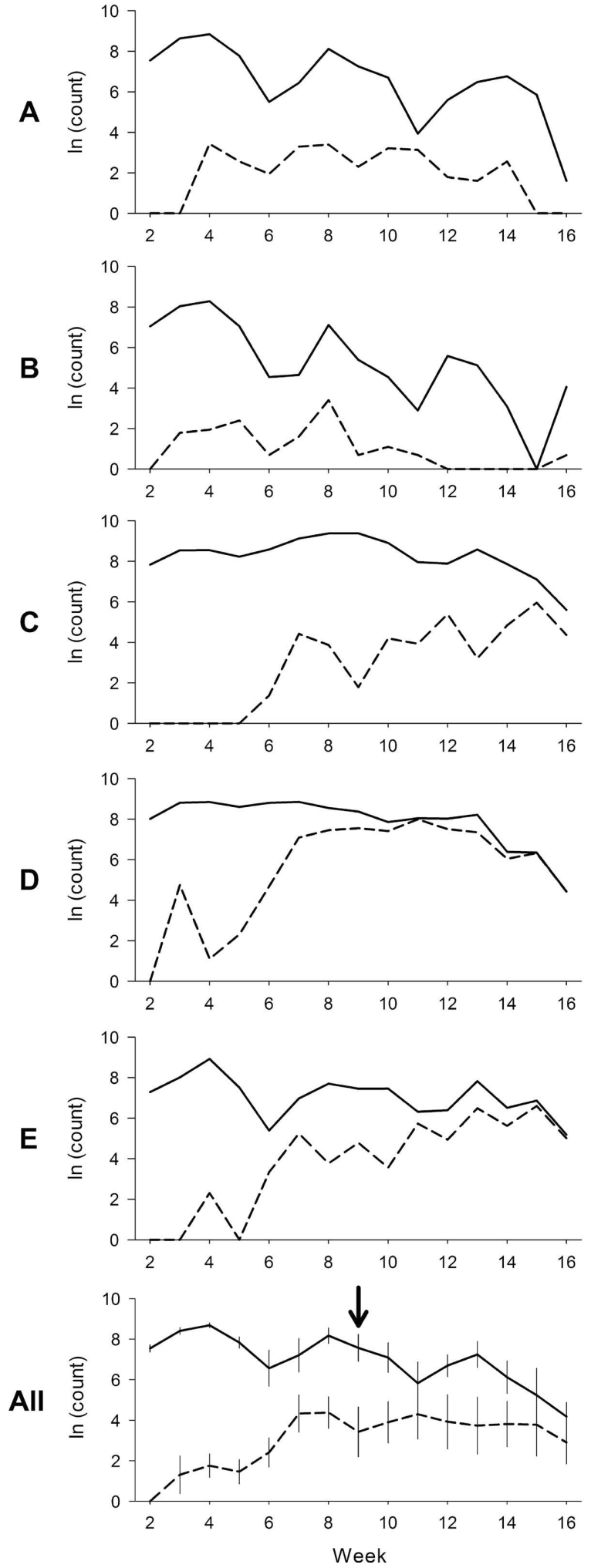

$\mathrm{H+}$
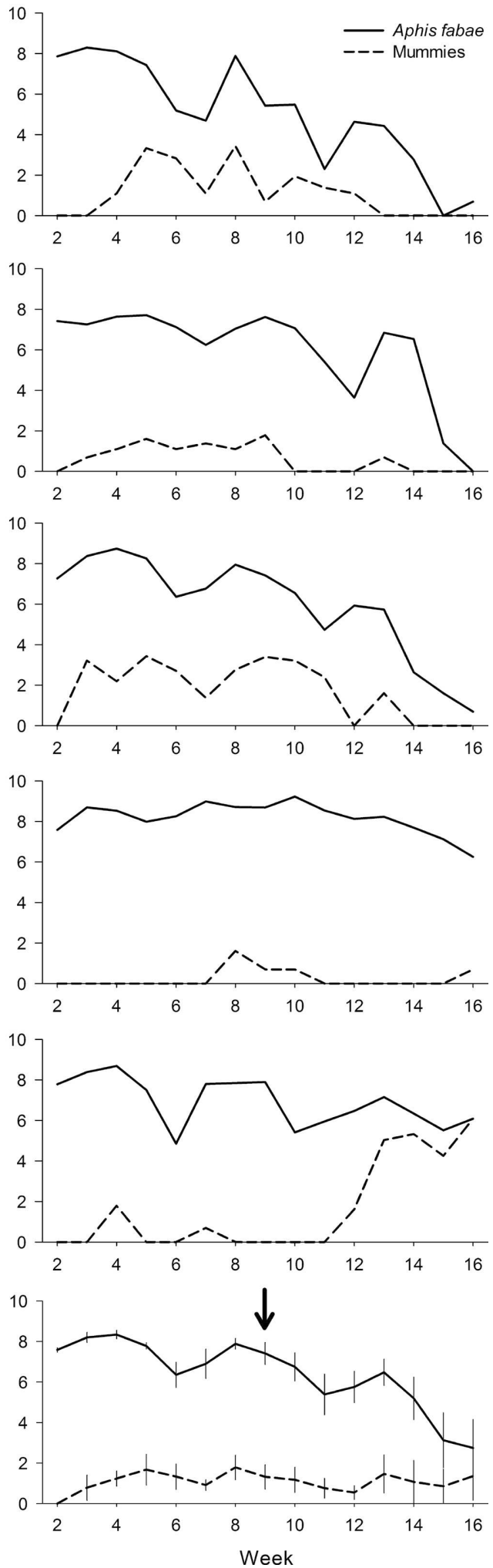

Fig. 1. Temporal trajectories of counts of Aphis fabae and A. fabae mummies over the course of the experiment for the 10 field plots, arranged by treatment and plot pair. The bottom panels show counts over all $\mathrm{H}-$ and $\mathrm{H}+$ plots (mean $\pm \mathrm{SE}$ ). Arrows indicate the time point when 36 aphids per plot were sampled and screened for the presence of Hamiltonella defensa to verify that treatment differences persisted. Treatments are described in Methods: Aphid lines. 
TABLE 1. Results of linear mixed effects models of the weekly counts of black bean aphids (Aphis fabae), of A. fabae mummies and of vetch aphids (Megoura viciae).

\begin{tabular}{|c|c|c|c|}
\hline Source & df & $\begin{array}{l}F \text { for fixed effects/ } \\
\text { LR } \chi_{1}^{2} \text { for random } \\
\text { effects }\end{array}$ & $P$ \\
\hline \multicolumn{4}{|l|}{$\begin{array}{l}\text { Number of Aphis } \\
\text { fabae }\end{array}$} \\
\hline Treatment & 1,4 & 0.984 & 0.377 \\
\hline Week & 14,112 & 16.031 & $<0.001$ \\
\hline Treatment $\times$ Week & 14,112 & 0.637 & 0.829 \\
\hline Plot pair & & 0.881 & 0.348 \\
\hline Plot (pair) & & 19.975 & $<0.001$ \\
\hline \multicolumn{4}{|l|}{$\begin{array}{l}\text { Number of } A \text {. fabae } \\
\text { mummies }\end{array}$} \\
\hline Treatment & 1,8 & 5.584 & 0.046 \\
\hline Week & 14,112 & 2.530 & 0.004 \\
\hline Treatment $\times$ week & 14,112 & 1.752 & 0.055 \\
\hline Plot pair & & 0.000 & 1.000 \\
\hline Plot (pair) & & 27.600 & $<0.001$ \\
\hline \multicolumn{4}{|l|}{$\begin{array}{l}\text { Number of Megoura } \\
\text { viciae }\end{array}$} \\
\hline Treatment & 1,8 & 1.636 & 0.270 \\
\hline Week & 14,112 & 1.345 & 0.193 \\
\hline Treatment $\times$ week & 14,112 & 0.246 & 0.999 \\
\hline Plot pair & & 0.278 & 0.598 \\
\hline Plot (pair) & & 20.617 & $<0.001$ \\
\hline
\end{tabular}

Note: Degrees of freedom are given for fixed effects only. LR, likelihood ratio.

dominant species $L$. fabarum, comprising $84.5 \%$ of all parasitoid wasps identified in this study and $92 \%$ of all primary parasitoids, resulted in a more even species distribution in parasitoids from $\mathrm{H}+$ plots. This was reflected in significantly higher Shannon and Simpson diversities in primary parasitoids and overall (Fig. 3B,C), while these indices did not differ significantly in secondary parasitoids (Fig. 3B,C).

\section{Discussion}

By exposing genetically identical aphids with and without the bacterial endosymbiont $H$. defensa to natural colonization by parasitoids in the field, we could demonstrate reduced parasitism of $H$. defensa-protected aphids. There is ample evidence from laboratory experiments for $H$. defensa's protective effect against parasitoids (e.g., Oliver et al. 2003, 2005, Vorburger et al. 2009, Schmid et al. 2012, but see Lukasik et al. 2013a) as well as correlative evidence from the field that is at least suggestive (Brady and White 2013), but this is to our knowledge the first field study providing experimental evidence for the effectiveness of symbiont-conferred resistance under natural conditions. Observing protection in the field is encouraging in the light of the rapidly increasing number of laboratory studies reporting microbiota-mediated protection in various systems, particularly in cases where endosymbionts could be employed to suppress the transmission of medically important pathogens (Hoffmann et al. 2011).

This field experiment also supported our prediction that by providing unequal protection against different parasitoids, $H$. defensa influences the species composition of the parasitoid community exploiting the aphid hosts. We thus observed a symbiont-mediated effect on food web diversity and complexity. By essentially excluding some species, $H$. defensa had a negative effect on species richness, but because the otherwise dominant species was excluded, the relative frequencies of primary parasitoids from protected aphids were more even, resulting in higher Shannon and Simpson diversities (Fig. 3). How could this change in structure affect community function? Apart from clearly reducing the flow of energy from herbivores to primary parasitoids, the presence of $H$. defensa also broke the strongest link between these trophic levels. Considering that few very strong interactions are considered detrimental to food web stability (Rooney and McCann 2012), this could potentially have a stabilizing effect. However, most natural populations are neither completely protected nor unprotected, but comprise a mixture of hosts with and without defensive symbionts (e.g., Vorburger et al. 2009, Smith et al. 2015). In this case, we would expect the availability of unprotected hosts to maintain high parasitoid diversity, while the

TABLE 2. Species of parasitoid wasps emerging from Aphis fabae mummies collected in the experimental plots with the total number of individuals obtained throughout the experiment.

\begin{tabular}{|c|c|}
\hline Species & Total number hatched \\
\hline \multicolumn{2}{|l|}{ Primary parasitoids } \\
\hline Aphelinus chaonia (A. cha.) & 198 \\
\hline Binodoxys acalephae (B. aca.) & 1 \\
\hline Binodoxys angelicae (B. ang.) & 99 \\
\hline Ephedrus plagiator (E. pla.) & 1 \\
\hline Lysiphlebus cardui (L. car.) & 152 \\
\hline Lysiphlebus confusus (L. con.) & 223 \\
\hline Lysiphlebus fabarum (L. fab.) & 8051 \\
\hline \multicolumn{2}{|l|}{ Secondary parasitoids } \\
\hline \multicolumn{2}{|l|}{ Hyperparasitoids } \\
\hline Alloxysta arcuata (Al. arc.) & 5 \\
\hline Alloxysta brevis (Al. bre.) & 34 \\
\hline Alloxysta mullensis (Al. mul.) & 1 \\
\hline Alloxysta pleuralis (Al. ple.) & 4 \\
\hline Alloxysta pusilla (Al. pus.) & 29 \\
\hline Alloxysta $\mathrm{sp}$. & 2 \\
\hline Phaenoglyphis villosa (Ph.vil.) & 2 \\
\hline \multicolumn{2}{|l|}{ Mummy parasitoids } \\
\hline Asaphes suspensus (As. sus.) & 17 \\
\hline Asaphes vulgaris (As. vul.) & 12 \\
\hline Dendrocerus carpenteri (D. car.) & 58 \\
\hline Dendrocerus laevis (D. lae.) & 8 \\
\hline Dendrocerus latipes (D. lat.) & 1 \\
\hline Pachyneuron aphidis (P. aph.) & 259 \\
\hline Syrphophagus aphidivorus (S. aph.) & 366 \\
\hline
\end{tabular}


H-
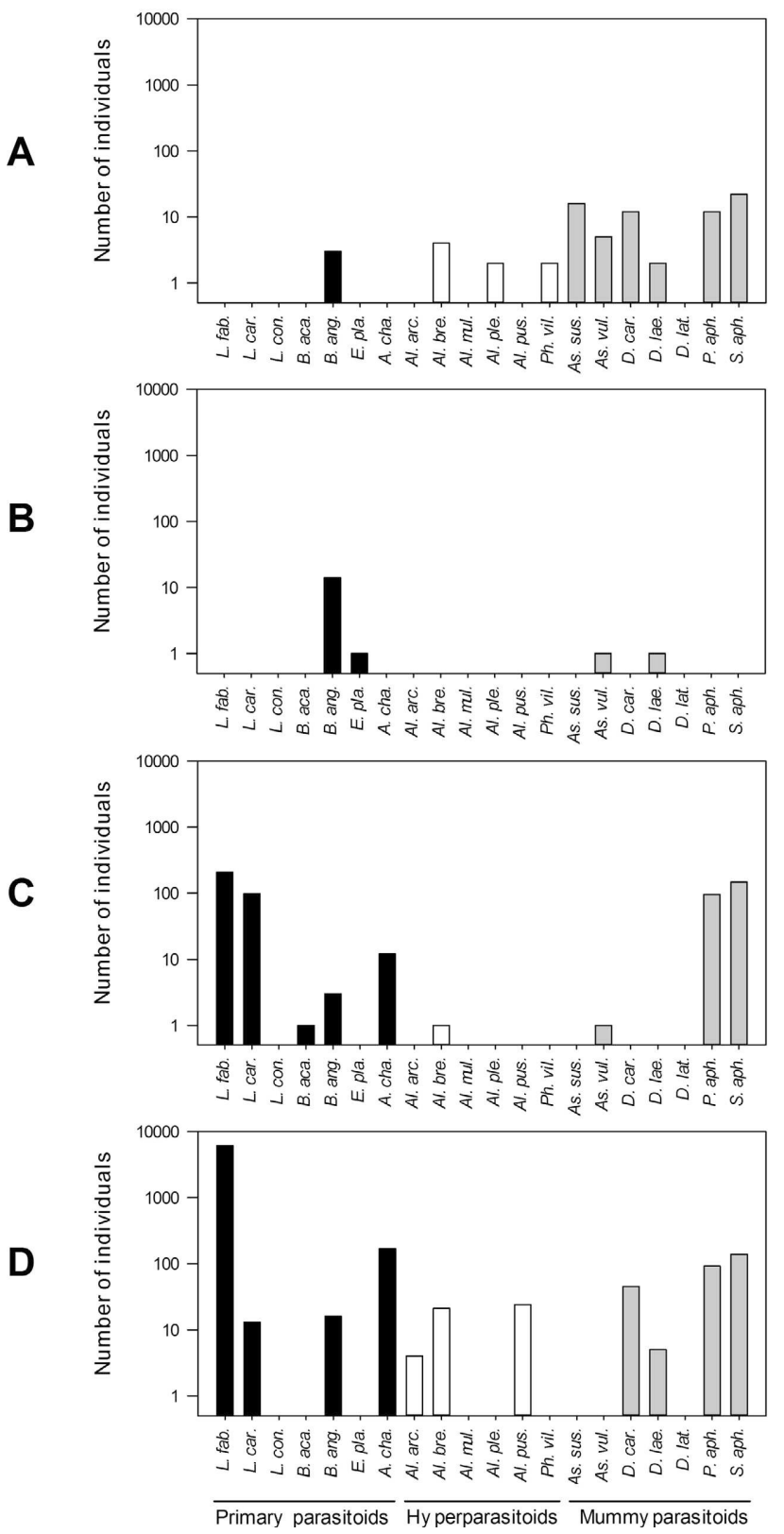

$\mathrm{H+}$
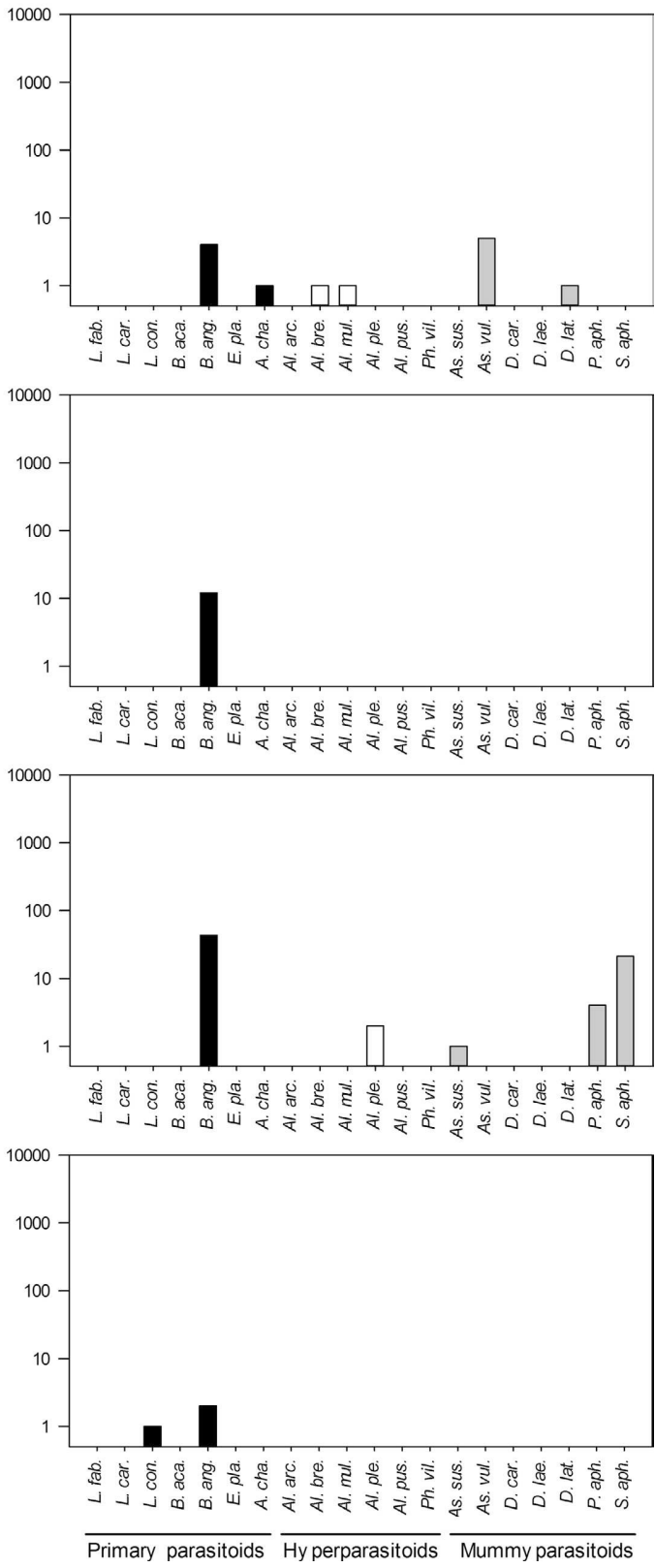

FIG. 2. Bar plots showing the numbers of individuals for the primary and secondary parasitoid species emerging from all Aphis fabae mummies collected from the 10 field plots. Panel All shows the total counts over all plots of the same treatment. Counts are depicted on a log-scale. For abbreviations of species names, see Table 2.

fraction of hosts resistant to the dominant parasitoids could weaken those particular links and shift the food web structure towards less skewed interaction strengths.

\section{Endosymbiont effects on aphid, parasitoid and predator numbers}

The possession of $H$. defensa did not have any obvious effects on the occurrence of other natural enemies of aphids and importantly, the reduced parasitism did not result in larger aphid populations in $\mathrm{H}+$ plots compared to $\mathrm{H}-$ plots. It is possible that parasitoid-induced mortality was too low in our experiment to have a detectable effect on aphid population sizes. In the most-affected plot, only $19 \%$ of the black bean aphids were mummified, parasitism was below $10 \%$ in the other $\mathrm{H}-$ plots and even below $1 \%$ in two of them (Appendix S1: Fig. S2b). Field surveys of $A$. fabae tend to report higher values, e.g., up to $30 \%$ 

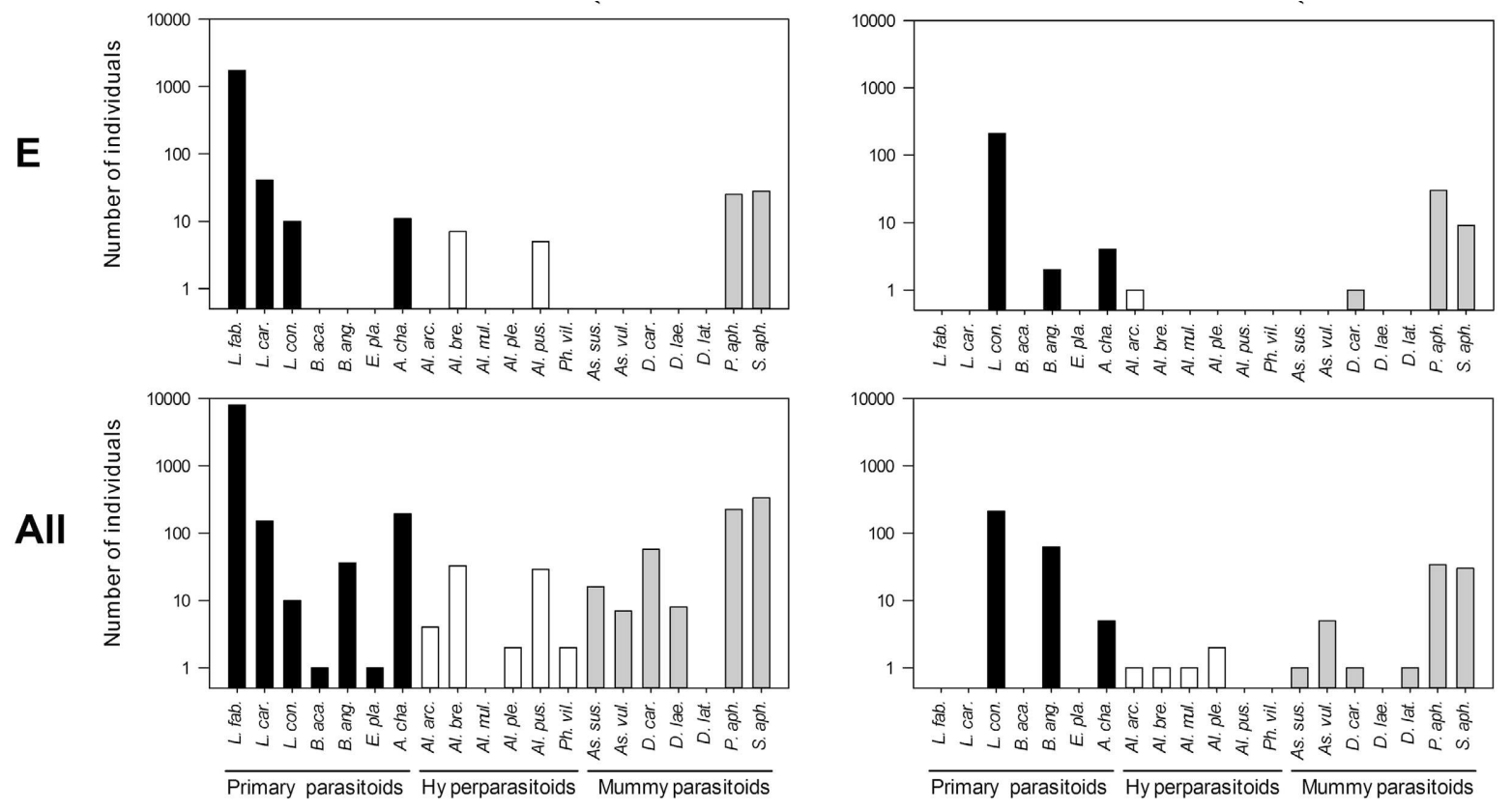

FIG. 2. (Continued).

on broad beans in Belgium (Verheggen et al. 2009), or between $5 \%$ and $80 \%$ (depending on season) on broad beans and other host plants in Germany (Völkl and Stechmann 1998). The comparatively low rates we observed may be due to the fact that we supplied new unparasitized aphids every week. Another factor to consider is that, in the absence of parasitoids, the possession of $H$. defensa can be associated with costs to the aphid host in terms of lower competitive ability (Oliver et al. 2008, Dykstra et al. 2014), reduced lifespan and lifetime reproduction (Vorburger and Gouskov 2011, Cayetano et al. 2015), or increased susceptibility to predators (Polin et al. 2014). Assuming that these costs, which were described under laboratory conditions, are also incurred in the field, rather strong selection by parasitoids may be required to provide a net benefit to aphids harboring $H$. defensa. A net benefit of defensive symbionts is certainly seen when aphids are exposed to high parasitoid pressure in laboratory populations (Herzog et al. 2007, Oliver et al. 2008).

The variation in parasitism among plots of the same treatment was very large in our experiment, presumably reflecting the high heterogeneity of the landscape they were placed in (see Appendix S1: Fig. S1). With their very low numbers of primary parasitoids even from unprotected aphids, plot pairs A and B behaved very differently from the other three pairs, and plot pair D clearly contributed most to the overall difference between treatments (Figs. 1 and 2). It is unclear what caused these differences, but we can speculate that light and temperature conditions might have played a role, because plot pairs $\mathrm{A}$ and $\mathrm{B}$ were adjacent to tall buildings and/or trees on their eastern and southern sides and therefore distinctly more shady than the other plot pairs (Appendix
S1: Fig. S1). It is certainly known that the surrounding vegetation and landscape structure can influence the colonization of aphid populations by parasitoids (e.g., Brewer et al. 2008). This implies that some of the variation between the $\mathrm{H}-$ and $\mathrm{H}+$ plots of the same pairs could also reflect differences in local colonization, because for fear of reciprocal migration diluting our treatments, we did not place the $\mathrm{H}-$ and $\mathrm{H}+$ plots immediately adjacent to each other. The control of treatment persistence by diagnostic PCR in week 9 of the experiment showed that our approach with a safety margin of $\geq 10 \mathrm{~m}$ might have been overly cautious and that similar experiments in the future could place experimental plots closer together to reduce this additional, idiosyncratic variation. Finding almost 16 times more mummies in $\mathrm{H}-$ plots compared to $\mathrm{H}+$ plots is nevertheless convincing evidence for protection by $H$. defens $a$ in the field.

\section{Endosymbiont effects on parasitoid species composition}

Selective protection by $H$. defensa appeared to be particularly effective against the species posing the highest risk: A. fabae's most important parasitoid L. fabarum. It comprised $92 \%$ of all primary parasitoids we collected but was only found in $\mathrm{H}-$ plots. Also restricted to $\mathrm{H}-$ plots was the congeneric L. cardui, yet L. confusus, another closely related species, was apparently able to parasitize protected aphids and was even more common on $\mathrm{H}+$. However, the vast majority of L. confusus came from just a single $\mathrm{H}+$ plot (Fig. 2), suggesting its higher frequency on $\mathrm{H}+$ aphids might reflect unequal colonization. So far, there is no experimental evidence from laboratory experiments that there are parasitoid species 
A) Species richness

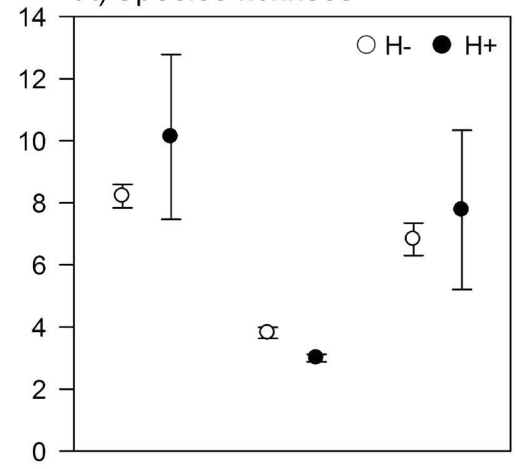

B) Shannon diversity

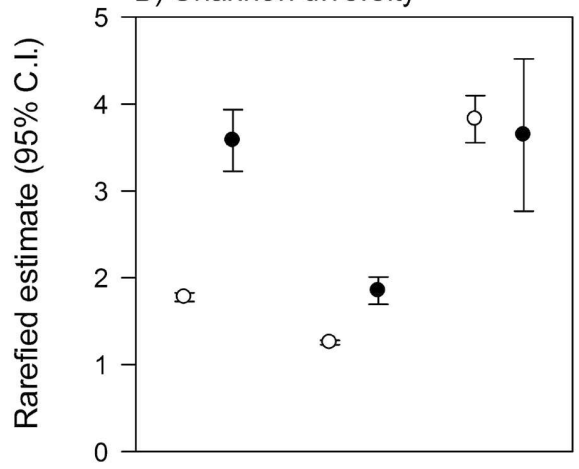

C) Simpson diversity

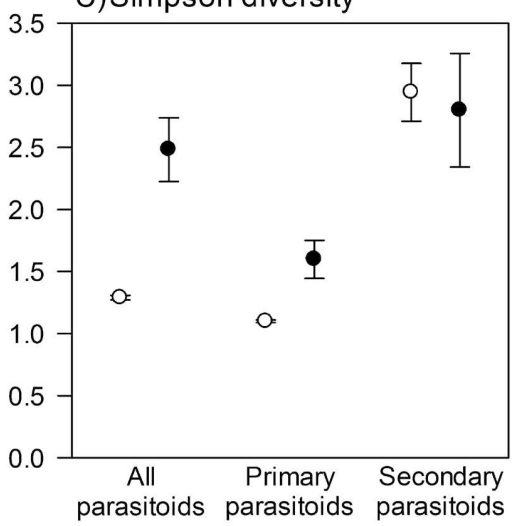

FIG. 3. Estimates of (A) species richness, (B) Shannon diversity, and (C) Simpson diversity with bootstrap 95\% confidence intervals for parasitoids obtained from $\mathrm{H}^{-}$(open symbols) and $\mathrm{H}+$ plots (solid symbols). Separate estimates are provided for all parasitoids combined, primary parasitoids, and secondary parasitoids. Estimates were obtained by rarefaction from the aggregated counts (sums over all five plots per treatment) using equal-sized samples $(n=200$ for primary parasitoids and all parasitoids combined, $n=50$ for secondary parasitoids). Differences between $\mathrm{H}-$ and $\mathrm{H}+$ are considered significant with $P<0.05$ when confidence intervals do not include the estimates for the other group.

that develop significantly better in $H$. defensa-protected aphids (Asplen et al. 2014, Cayetano and Vorburger 2015). Please note that for consistency with the taxonomic literature (e.g., Starý 2006) we refer to L. fabarum,
L. cardui, and $L$. confusus as separate species, even though more recent studies have shown that they are part of a poorly resolved species complex, the " $L$. fabarum group," with predominantly asexual reproduction (Sandrock et al. 2011, Petrović et al. 2015). Accordingly, we observed strongly biased sex ratios of $99.4 \%$ females in L. fabarum, $100 \%$ females in $L$. cardui, and $98.7 \%$ females in $L$. confusus. Despite their uncertain taxonomic status, it makes sense to discern these morphologically distinguishable lineages, because they tend to show ecological differences (Sandrock et al. 2011), and because different asexual lines of this group exhibit variation in their ability to parasitize $H$. defensa-protected aphids (e.g., Rouchet and Vorburger 2012, Cayetano et al. 2015). The asexual $L$. confusus we collected are likely to represent a lineage able to overcome the resistance conferred by $H$. defens $a$ at least to some extent. The only other primary parasitoid obtained in relatively large numbers from mummies of protected aphids was $B$. angelicae, the only species found in all five $\mathrm{H}+$ plots. It appears to be capable of developing in aphids possessing $H$. defensa, which would be consistent with an earlier result showing no significant protection of $A$. fabae by $H$. defensa against $B$. angelicae (Cayetano and Vorburger 2015). This may not be generally true for parasitoids of the genus Binodoxys, however, because Asplen et al. (2014) reported strong $H$. defensa-mediated protection of cowpea aphids (A. craccivora) against two other species of the same genus, $B$. communis and $B$. koreanus. From the second group of aphid primary parasitoids, the Aphelinidae, only one species was found, Aphelinus chaonia. Nearly all individuals came from $\mathrm{H}-$ plots, suggesting that $H$. defensa also provides some protection against $A$. chaonia. A recent laboratory experiment with black bean aphids failed to demonstrate protection against this species, albeit inconclusively due to very low parasitism even in unprotected aphids (Cayetano and Vorburger 2015). Symbiont-conferred resistance against aphelinid parasitoids is certainly feasible, because in pea aphids, four isolates of $H$. defensa were discovered that protect strongly against the congeneric species A. abdominalis, a frequently used biocontrol agent (McLean and Godfray 2015).

The primary parasitoids exploiting $A$. fabae in our field plots supported an astonishingly diverse community of 13 secondary parasitoid species. Relying on the presence of primary parasitoids for development, they were of course much less abundant in $\mathrm{H}+$ plots than in $\mathrm{H}-$ plots. This precluded detailed comparisons, but the general patterns suggested similar species diversities of secondary parasitoids in both treatments, unlike in primary parasitoids.

\section{A link from host plants to parasitoids via aphid endosymbionts?}

Effects of host plant traits cascading upward to affect the structure and composition of the parasitoid and 
TABLE 3. Comparisons of frequencies of the five most abundant primary parasitoid species between $\mathrm{H}-$ and $\mathrm{H}+$ plots.

\begin{tabular}{|c|c|c|c|c|c|c|}
\hline Species and plot pair & $\mathrm{H}-$ & $\mathrm{H}+$ & $G$ statistic & $P$ & Heterogeneity $G$ & $P$ \\
\hline \multicolumn{7}{|l|}{ L. fabarum } \\
\hline $\mathrm{A}$ & 0 & 0 & 0.000 & 1.000 & & \\
\hline $\mathrm{B}$ & 0 & 0 & 0.000 & 1.000 & & \\
\hline $\mathrm{C}$ & 208 & 0 & 288.349 & $<0.001$ & & \\
\hline $\mathrm{D}$ & 6119 & 0 & 8482.735 & $<0.001$ & & \\
\hline $\mathrm{E}$ & 1724 & 0 & 2389.971 & $<0.001$ & & \\
\hline All & 8051 & 0 & 11161.056 & $<0.001$ & 0.000 & 0.998 \\
\hline \multicolumn{7}{|l|}{ L. cardui } \\
\hline A & 0 & 0 & 0.000 & 1.000 & & \\
\hline $\mathrm{B}$ & 0 & 0 & 0.000 & 1.000 & & \\
\hline $\mathrm{C}$ & 98 & 0 & 135.857 & $<0.001$ & & \\
\hline $\mathrm{D}$ & 13 & 0 & 18.022 & $<0.001$ & & \\
\hline $\mathrm{E}$ & 41 & 0 & 56.838 & $<0.001$ & & \\
\hline All & 152 & 0 & 210.717 & $<0.001$ & 0.000 & 0.998 \\
\hline \multicolumn{7}{|l|}{ L. confusus } \\
\hline A & 0 & 0 & 0.000 & 1.000 & & \\
\hline $\mathrm{B}$ & 0 & 0 & 0.000 & 1.000 & & \\
\hline $\mathrm{C}$ & 0 & 0 & 0.000 & 1.000 & & \\
\hline $\mathrm{D}$ & 0 & 1 & 1.386 & 0.239 & & \\
\hline $\mathrm{E}$ & 10 & 212 & 226.213 & $<0.001$ & & \\
\hline All & 10 & 213 & 227.507 & $<0.001$ & 0.092 & 0.762 \\
\hline \multicolumn{7}{|l|}{ B. angelicae } \\
\hline A & 3 & 4 & 0.143 & 0.705 & & \\
\hline $\mathrm{B}$ & 14 & 12 & 0.154 & 0.695 & & \\
\hline $\mathrm{C}$ & 3 & 43 & 41.589 & $<0.001$ & & \\
\hline $\mathrm{D}$ & 16 & 2 & 12.395 & $<0.001$ & & \\
\hline $\mathrm{E}$ & 0 & 2 & 2.773 & 0.096 & & \\
\hline All & 36 & 63 & 7.458 & 0.006 & 49.597 & $<0.001$ \\
\hline \multicolumn{7}{|l|}{ A. chaonia } \\
\hline A & 0 & 1 & 1.386 & 0.239 & & \\
\hline $\mathrm{B}$ & 0 & 0 & 0.000 & 1.000 & & \\
\hline $\mathrm{C}$ & 12 & 0 & 16.636 & $<0.001$ & & \\
\hline $\mathrm{D}$ & 170 & 0 & 235.670 & $<0.001$ & & \\
\hline $\mathrm{E}$ & 11 & 4 & 3.397 & 0.065 & & \\
\hline All & 193 & 5 & 227.825 & $<0.001$ & 29.264 & $<0.001$ \\
\hline
\end{tabular}

Notes: Individual $G$ tests for each plot pair as well as a pooled test over all plot pairs are presented. The heterogeneity $G$ tests indicate whether relative frequencies were consistent among different plot pairs. $\mathrm{H}-$ and $\mathrm{H}+$ treatments are described in Methods: Aphid lines.

hyperparasitoid food web exploiting aphid hosts have been demonstrated convincingly (Omacini et al. 2001, Bukovinszky et al. 2008). We propose that selective protection by endosymbionts is an additional type of bottom-up effect that also influences the community composition of parasitoids. This is particularly interesting because host specialization in aphids is often associated with changes in their microbiome. Pea aphids (Acyrthosiphon pisum), for example, have evolved numerous host races that show at least partial reproductive isolation and are specialized on different legume genera (Peccoud et al. 2009). These host races differ strongly in the relative frequencies of different bacterial endosymbionts they harbor (Ferrari et al. 2012). A similar observation was made for hostassociated populations of the cowpea aphid, Aphis craccivora (Brady and White 2013). Although plant traits can undoubtedly have significant effects on aphid-parasitoid food webs, our results suggest that bacterial endosymbionts should also be considered when plant-associated variation in such food webs is examined.

\section{ACKNOWLEDGMENTS}

We wish to thank L. Cayetano, H. Käch, and R. Sieber for their assistance with the field experiment, S. von Burg Black for help with parasitoid species identification, and especially P. Rodriguez for maintaining the laboratory collection of aphid lines. This study was supported by the Swiss National Science Foundation (SNSF Professorship nr. PP00P3_146341 and Sinergia grant nr. CRSII3_154396 to C. Vorburger). The work of M. Ferrer-Suay is funded by a post-doctoral contract of The 
Kalbfleisch Fellowship, Richard Gilder Graduate School, American Museum of Natural History.

\section{Literature Cited}

Asplen, M. K., N. Bano, C. M. Brady, N. Desneux, K. R. Hopper, C. Malouines, K. M. Oliver, J. A. White, and G. E. Heimpel. 2014. Specialisation of bacterial endosymbionts that protect aphids from parasitoids. Ecological Entomology 39:736-739.

Bates, D., M. Maechler, B. Bolker, and S. Walker. 2015. Fitting linear mixed-effects models using lme4. Journal of Statistical Software 67:1-48.

Blackman, R. L., and V. F. Eastop. 2000. Aphids on the World's crops: an identification and information guide. Second edition. John Wiley and Sons, Chichester, UK.

Brady, C. M., and J. A. White. 2013. Cowpea aphid (Aphis craccivora) associated with different host plants has different facultative endosymbionts. Ecological Entomology 38:433- 437.

Brewer, M. J., T. Noma, N. C. Elliott, A. N. Kravchenko, and A. L. Hild. 2008. A landscape view of cereal aphid parasitoid dynamics reveals sensitivity to farm- and region-scale vegetation structure. European Journal of Entomology 105: 503-511.

Bukovinszky, T., F. J. F. van Veen, Y. Jongema, and M. Dicke. 2008. Direct and indirect effects of resource quality on food web structure. Science 319:804-807.

Cayetano, L., and C. Vorburger. 2013. Genotype-by-genotype specificity remains robust to average temperature variation in an aphid/endosymbiont/parasitoid system. Journal of Evolutionary Biology 26:1603-1610.

Cayetano, L., and C. Vorburger. 2015. Symbiont-conferred protection against Hymenopteran parasitoids in aphids: how general is it? Ecological Entomology 40:85-93.

Cayetano, L., L. Rothacher, J. C. Simon, and C. Vorburger. 2015. Cheaper is not always worse: strongly protective isolates of a defensive symbiont are less costly to the aphid host. Proceedings of the Royal Society B 282:20142333.

Douglas, A. E. 1998. Nutritional interactions in insect-microbial symbioses: aphids and their symbiotic bacteria Buchnera. Annual Review of Entomology 43:17-37.

Dykstra, H. R., S. R. Weldon, A. J. Martinez, J. A. White, K. R. Hopper, G. E. Heimpel, M. K. Asplen, and K. M. Oliver. 2014. Factors limiting the spread of the protective symbiont Hamiltonella defensa in Aphis craccivora aphids. Applied and Environmental Microbiology 80:5818-5827.

Ferrari, J., J. A. West, S. Via, and H. C. J. Godfray. 2012. Population genetic structure and secondary symbionts in host-associated populations of the pea aphid complex. Evolution 66:375-390.

Hansen, A. K., G. Jeong, T. D. Paine, and R. Stouthamer. 2007. Frequency of secondary symbiont infection in an invasive psyllid relates to parasitism pressure on a geographic scale in California. Applied and Environmental Microbiology 73:7531-7535.

Hedges, L. M., J. C. Brownlie, S. L. O'Neill, and K. N. Johnson. 2008. Wolbachia and virus protection in insects. Science 322:702.

Henry, L. M., M. C. J. Maiden, J. Ferrari, and H. C. J. Godfray. 2015. Insect life history and the evolution of bacterial mutualism. Ecology Letters 18:516-525.

Herzog, J., C. B. Müller, and C. Vorburger. 2007. Strong parasitoid-mediated selection in experimental populations of aphids. Biology Letters 3:667-669.

Hoffmann, A. A., et al. 2011. Successful establishment of Wolbachia in Aedes populations to suppress dengue transmission. Nature 476:454-457.
Hsieh, T. C., K. H. Ma, and A. Chao. 2014. iNEXT: iNterpolation and EXTrapolation for species diversity. R package version 2.0. http://chao.stat.nthu.edu.tw/blog/software-download

Jaenike, J., R. Unckless, S. N. Cockburn, L. M. Boelio, and S. J. Perlman. 2010. Adaptation via symbiosis: recent spread of a Drosophila defensive symbiont. Science 329:212-215.

Kambris, Z., A. M. Blagborough, S. B. Pinto, M. S. C. Blagrove, H. C. J. Godfray, R. E. Sinden, and S. P. Sinkins. 2010. Wolbachia stimulates immune gene expression and inhibits Plasmodium development in Anopheles gambiae. PLoS Pathogens 6:e1001143.

Kellner, R. L. L., and K. Dettner. 1996. Differential efficacy of toxic pederin in deterring potential arthropod predators of Paederus (Coleoptera: Staphylinidae) offspring. Oecologia 107:293-300.

Kuznetsova, A., P. B. Brockhoff, and R. H. B. Christensen. 2015. lmerTest: Tests in Linear Mixed Effects Models. R package version 2.0-29. http://CRAN.R-project.org/package=lmerTest

Łukasik, P., M. A. Dawid, J. Ferrari, and H. C. J. Godfray. 2013a. The diversity and fitness effects of infection with facultative endosymbionts in the grain aphid, Sitobion avenae. Oecologia 173:985-996.

Łukasik, P., H. Guo, M. Van Asch, J. Ferrari, and H. C. J. Godfray. 2013b. Protection against a fungal pathogen conferred by the aphid facultative endosymbionts Rickettsia and Spiroplasma is expressed in multiple host genotypes and species and is not influenced by co-infection with another symbiont. Journal of Evolutionary Biology 26:2654-2661.

McLean, A. H. C., and H. C. J. Godfray. 2015. Evidence for specificity in symbiont-conferred protection against parasitoids. Proceedings of the Royal Society B 282:20150977.

Moran, N. A., J. A. Russell, R. Koga, and T. Fukatsu. 2005. Evolutionary relationships of three new species of Enterobacteriaceae living as symbionts of aphids and other insects. Applied and Environmental Microbiology 71:3302-3310.

Morris, R. J., O. T. Lewis, and H. C. J. Godfray. 2004. Experimental evidence for apparent competition in a tropical forest food web. Nature 428:310-313.

Müller, C. B., I. C. T. Adriaanse, R. Belshaw, and H. C. J. Godfray. 1999. The structure of an aphid-parasitoid community. Journal of Animal Ecology 68:346-370.

Oliver, K. M., J. A. Russell, N. A. Moran, and M. S. Hunter. 2003. Facultative bacterial symbionts in aphids confer resistance to parasitic wasps. Proceedings of the National Academy of Sciences USA 100:1803-1807.

Oliver, K. M., N. A. Moran, and M. S. Hunter. 2005. Variation in resistance to parasitism in aphids is due to symbionts not host genotype. Proceedings of the National Academy of Sciences USA 102:12795-12800.

Oliver, K. M., J. Campos, N. A. Moran, and M. S. Hunter. 2008. Population dynamics of defensive symbionts in aphids. Proceedings of the Royal Society B 275:293-299.

Oliver, K. M., P. H. Degnan, M. S. Hunter, and N. A. Moran. 2009. Bacteriophages encode factors required for protection in a symbiotic mutualism. Science 325:992-994.

Oliver, K. M., P. H. Degnan, G. R. Burke, and N. A. Moran. 2010. Facultative symbionts in aphids and the horizontal transfer of ecologically important traits. Annual Review of Entomology 55:247-266.

Oliver, K. M., A. H. Smith, and J. A. Russell. 2014. Defensive symbiosis in the real world-advancing ecological studies of heritable, protective bacteria in aphids and beyond. Functional Ecology 28:341-355.

Omacini, M., E. J. Chaneton, C. M. Ghersa, and C. B. Muller. 2001. Symbiotic fungal endophytes control insect hostparasite interaction webs. Nature 409:78-81. 
Peccoud, J., A. Ollivier, M. Plantegenest, and J. C. Simon. 2009. A continuum of genetic divergence from sympatric host races to species in the pea aphid complex. Proceedings of the National Academy of Sciences USA 106:7495-7500.

Petrović, A., M. Mitrović, A. Ivanović, V. Žikić, N. G. Kavallieratos, P. Starý, A. M. Bogdanović, Ž. Tomanović, and C. Vorburger. 2015. Genetic and morphological variation in sexual and asexual parasitoids of the genus Lysiphlebus - an apparent link between wing shape and reproductive mode. BMC Evolutionary Biology 15:5.

Polin, S., J. C. Simon, and Y. Outreman. 2014. An ecological cost associated with protective symbionts of aphids. Ecology and Evolution 4:826-830.

R Core Team. 2015. R: a language and environment for statistical computing. R Foundation for Statistical Computing, Vienna, Austria. http://www.R-project.org

Rooney, N., and K. S. McCann. 2012. Integrating food web diversity, structure and stability. Trends in Ecology \& Evolution 27:40-46.

Rouchet, R., and C. Vorburger. 2012. Strong specificity in the interaction between parasitoids and symbiont-protected hosts. Journal of Evolutionary Biology 25:2369-2375.

Rowell-Rahier, M., and J. M. Pasteels. 1992. Third trophic level influences of plant allelochemicals. Pages 243-277 in G. A. Rosenthal, and M. R. Berenbaum, editors. Herbivores: their interactions with secondary plant metabolites. Second edition, VolumeII: Ecological and evolutionary processes. Academic Press, San Diego, California, USA.

Russell, J. A., S. Weldon, A. H. Smith, K. L. Kim, Y. Hu, P. Lukasik, S. Doll, I. Anastopoulos, M. Novin, and K. M. Oliver. 2013. Uncovering symbiont-driven genetic diversity across North American pea aphids. Molecular Ecology 22:2045-2059.

Sandrock, C., B. E. Schirrmeister, and C. Vorburger. 2011. Evolution of reproductive mode variation and host associations in a sexual-asexual complex of aphid parasitoids. BMC Evolutionary Biology 11:348.

Scarborough, C. L., J. Ferrari, and H. C. J. Godfray. 2005. Aphid protected from pathogen by endosymbiont. Science 310:1781.

Schmid, M., R. Sieber, Y. S. Zimmermann, and C. Vorburger. 2012. Development, specificity and sublethal effects of symbiont-conferred resistance to parasitoids in aphids. Functional Ecology 26:207-215.

Smith, A. H., et al. 2015. Patterns, causes and consequences of defensive microbiome dynamics across multiple scales. Molecular Ecology 24:1135-1149.

Sokal, R. R., and F. J. Rohlf. 1995. Biometry. Third edition. Freeman, New York, New York, USA.
Stadler, B., and A. F. G. Dixon. 2005. Ecology and evolution of aphid-ant interactions. Annual Review of Ecology Evolution and Systematics. Annual Reviews 36:345-372.

Starý, P. 2006. Aphid parasitoids of the Czech Republic (Hymenoptera: Braconidae, Aphidiinae). Academia, Praha, Czech Republic.

Teixeira, L., A. Ferreira, and M. Ashburner. 2008. The bacterial symbiont Wolbachia induces resistance to RNA viral infections in Drosophila melanogaster. PLoS Biology 6: 2753-2763.

van Veen, F. J. F., P. D. van Holland, and H. C. J. Godfray. 2005. Stable coexistence in insect communities due to density- and trait-mediated indirect effects. Ecology 86:31823189.

Venables, W. N., and B. D. Ripley. 2002. Modern applied statistics with S. Springer, New York, New York, USA.

Verheggen, F., L. Diez, C. Detrain, and E. Haubruge. 2009. Aphid - ant mutualism: an outdoor study of the benefits for Aphis fabae. Biotechnologie Agronomie Société et Environnement 13:235-242.

Völk1, W., and D. H. Stechmann. 1998. Parasitism of the black bean aphid (Aphis fabae) by Lysiphlebus fabarum (Hym., Aphidiidae): the influence of host plant and habitat. Journal of Applied Entomology 122:201-206.

Vorburger, C. 2014. The evolutionary ecology of symbiontconferred resistance to parasitoids in aphids. Insect Science $21: 251-264$.

Vorburger, C., and A. Gouskov. 2011. Only helpful when required: a longevity cost of harbouring defensive symbionts. Journal of Evolutionary Biology 24:1611-1617.

Vorburger, C., C. Sandrock, A. Gouskov, L. E. Castañeda, and J. Ferrari. 2009. Genotypic variation and the role of defensive endosymbionts in an all-parthenogenetic host-parasitoid interaction. Evolution 63:1439-1450.

Vorburger, C., L. Gehrer, and P. Rodriguez. 2010. A strain of the bacterial symbiont Regiella insecticola protects aphids against parasitoids. Biology Letters 6:109-111.

Weinert, L. A., E. V. Araujo-Jnr, M. Z. Ahmed, and J. J. Welch. 2015. The incidence of bacterial endosymbionts in terrestrial arthropods. Proceedings of the Royal Society B 282:6.

Xie, J. L., B. Tiner, I. Vilchez, and M. Mateos. 2011. Effect of the Drosophila endosymbiont Spiroplasma on parasitoid wasp development and on the reproductive fitness of wasp-attacked fly survivors. Evolutionary Ecology 25:1065-1079.

Zytynska, S. E., and W. W. Weisser. 2016. The natural occurrence of secondary bacterial symbionts in aphids. Ecological Entomology 41:13-26.

\section{SUPPORTING INFORMATION}

Additional supporting information may be found in the online version of this article at http://onlinelibrary.wiley.com/ doi/10.1890/15-2022.1/suppinfo 